\title{
Effect of Load Shedding Strategy on Interconnected Power Systems Stability When a Blackout Occurs
}

\author{
Ghazanfar Shahgholian, Member, IACSIT, Mahdi Ebrahimi Salary
}

\begin{abstract}
From the long time ago properly and reliable operation of power systems were being the major portion of designer's and operators concernment. In the interconnected power systems voltage and frequency of system are most significant parameters for analysis the power system operation. In this paper sudden blackouts in a supposition interconnected power system will be simulate and effect of under frequency load shedding to restore the power system in stable condition will be study.
\end{abstract}

Index Terms-Frequency load shedding; interconnected power system; stability; frequency relays.

\section{INTRODUCTION}

Blackouts of power systems always have been a historical problem in interconnected power systems. However in recent years by improving monitoring and protection techniques, it is not possible to completely prevent of blackouts [1-2]. Sudden and large changes in generation capacity such as the outage of a generator can produce a sever imbalance between generation and load demand. This may lead to a rapid decline in frequency, because the system may not respond fast enough. If voltage and frequency are get out from permissible range that means the system is in unstable condition. In this condition the system controller's are operate and attempt to restore the voltage and frequency in the permissible range. If the disturbance is so large the controller's cant restore the voltage and frequency in the permissible range. In this condition the last solution to avoid the power system breakdown has been load shedding strategy. Blackout of generation units is one of critical disturbances that may occur in the interconnected power systems. In this condition frequency and voltage of power system are rapidly decline and other generation units will be over load. If the other generation units can't suffer this condition, they will be blackout once to once. Blackouts have irreparable economic effects on interconnected power systems. In this paper effect of load shedding strategy on restoring the power system in stable condition and preventing of other blackout in power system will be study. The system may even collapse in sever imbalances. Rapid and selective shedding of loads from the system may be a good option to restore the balance and maintain the system frequency [3].

When a power system is exposed to a disturbance, its dynamic and transient responses are control by two major dynamic loops. These loops are: (A) excitation loop (includ-

Manuscript received January 16, 2012; revised March 28, 2012.

Gh. Shahgholian and M. Ebrahimi Salary are with the Department of Electrical Engineering, Najafabad Branch, Islamic Azad University, Esfahan, Iran. (e-mail: shahgholian@iaun.ac.ir). ing AVR), this loop will control the generator reactive power and voltage. The excitation loop is operating via the excitation current regulation. And (B) frequency loop (including LFC), when the system is exposed to a disturbance this loop is control active power and frequency of system. This loop is operating via regulating of Governor.

\section{DESCRIPTION OF LOAD SHEDDING}

One of the important requirements in power system is to ensure that sufficient power is generated to meet load demand under normal and emergency conditions. Under normal power system operation the system is kept balance by providing a supply of generation that meet the load demand and system's losses as given in equation below [4]:

$$
\text { Total Generation }=\text { Total load }+ \text { Total loss }
$$

Under this balance condition the system will operates at the synchronous frequency of 50 or $60 \mathrm{~Hz}$. In the event of that this balanced state is disturbed, the system frequency changes as in Table I.

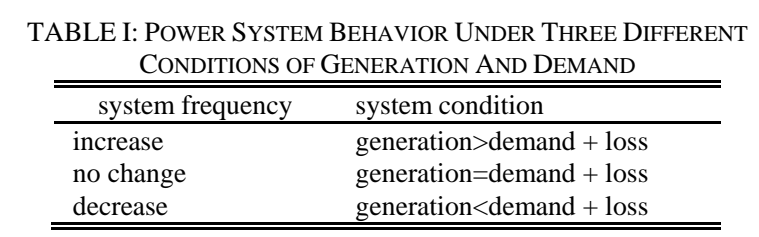

The decline in frequency is due to in sufficient a mount of generation that meet load demand. This will cause the load to acquire power from the stored kinetic energy in a rotating system and causes the slowing rotation. Slowing rotation resulting in the frequency and cause the frequency is decline. Most electrical machines are designed to operate under frequency of 60 or $50 \mathrm{~Hz}$.any frequency violation may cause damage to the machines. In this condition load shedding is the best strategy to prevent the system breakdown extension. Therefore the stresses that influence power system are decay $[5]$.

\section{METHODS OF LOAD SHEDDING}

In this section a number of load shedding schemes is present. Each system has its own set of application and drawbacks.

\section{A. Breaker Interlock Scheme}

This method is the simplest method in respect to the other load shedding schemes .for example a source Breaker would be interlock via hard wired or remote signals to a set of load 
breakers that have been pre-selected to trip. When a Generator breaker or a grid connection is lost for any reason, signals are automatically sent to load breakers to open. This system is very fast since there is no processing required and all decisions about the amount of load to be shed were made long before the fault occurred. In Figure 1 the load is supplied by a combination of a generator and a power grid. A disturbance out side the facility causes the main breaker to operate and open.This would isolate the system from the power grid causing the system load to be supplied solely by the local generator. Opening of the main breaker would signal the interlocked load breaker to trip without any intentional time delay. This pre-selected breaker interlock list is typically determined without any knowledge of system transient response and is often resulting unnecessary load shedding.

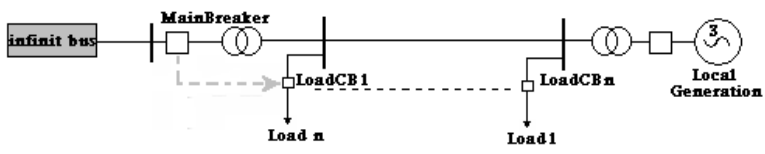

Fig. 1. Breaker interlock load shedding scheme

\section{B. Under Frequency Relay Scheme}

Frequency Relay detects any rapid change in frequency and initiate staged operation of interlocked breakers. When the first stage is reached, the relay waits a predetermined amount of time to avoid nuisance tripping and then trips one or more load breakers. If the frequency continues to decay, the relay will wait for the next stage to be reached and after an additional time delay opens other load breakers. For the system shown in Figure 2, the frequency relay detects the first load shedding stage and the interlocked load circuit breakers are tripped accordingly, which will reduce the real and reactive power demand on the generator. If the frequency continues to decay then subsequent load shedding stages will be reached and additional load breakers will be tripped until frequency returns to normal [6].

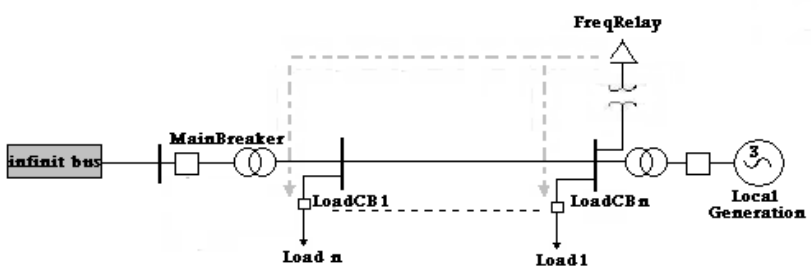

Fig. 2. Under frequency Load shedding scheme

\section{Programmable Logic Controller Based Load Shedding}

The use of programmable logic controller (PLCs) for automatic sequencing of load has become an important part of substation automation in recent years. The application of PLCs in industrial load management and curtailment schemes started in early 1980s. With a common type of PLC-based load shedding scheme, load shedding is initiated based on the system frequency deviations and/or other triggers .the circuit breaker tripping can be programmed based on the system loading, available generations, and other triggers. Each subsystem is equipped with a PLC that is programmed to shed a preset sequence of loads. This static sequence is continued until the frequency returns to normal condition PLC based load shedding scheme offers many advantages over the frequency-based scheme since they have access to information about the actual operating status of power system. However monitoring of the power system is limited to the section of the system that are connected to the data acquisition system .This drawback is further compounded by the implementation of pre-defined load priority tables in the PLC. These load reduction tables are executed sequentially to curtail blocks of load until a preset load shedding level is achieved. This process may be independent of the dynamic changes in the system loading, generation or operating configure ration. The system-wide operating conditions are often missing from the PLC's decision-making process resulting in insufficient or excessive load shedding. In addition, the load shedding system response time during transient disturbance is often too long requiring for even more load to be dropped.

\section{Intelligent Load Shedding (ILS)}

Due to the inherent drawbacks of existing load shedding methods, an intelligent load shedding system is necessary to improve the response time, accurately predict the system frequency decay, and make a fast, optimum and reliable load shedding decision.

In Figure 3, the system knowledge base is pre-trained by using carefully selected input and output data bases from offline system studies and simulations .based on the input data and system updates, the knowledge base periodically sends requests to the ILS computation engine to update the load shedding tables, Thus ensuring that the optimum load will be shed should when a disturbance occur. Load shedding tables are downloaded to the Distributed controls that are located close to each shed able load. When a disturbance occurs, fast load shedding action can be taken. ILS knowledge base and computation engine reside in an ILS server computer. The server interfaces with an advanced real-time power system monitoring and simulation system that continuously acquires real-time system data. Based on ILS calculations, the server dynamically updates the load shedding tables and downloads that information to the distributed PLCs. Upon detection of any disturbance by the PLCs, load shedding is initiated.

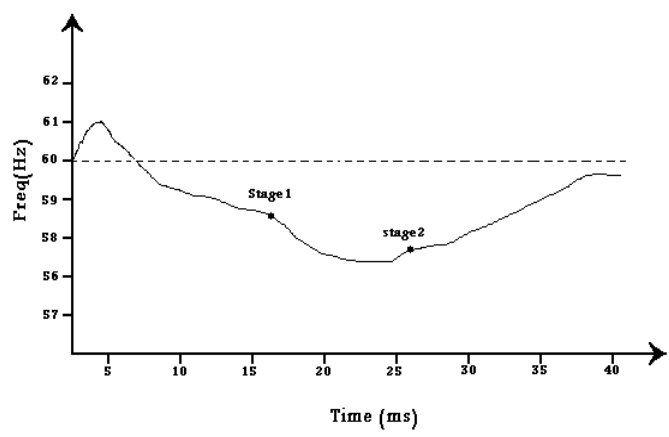

Fig. 3. System frequency in under frequency load shedding

A comparison of ILS system response time with frequency relay load shedding is illustrated in Figure 4. As shown the total response time for the frequency relay based load shedding is much longer than ILS system. 


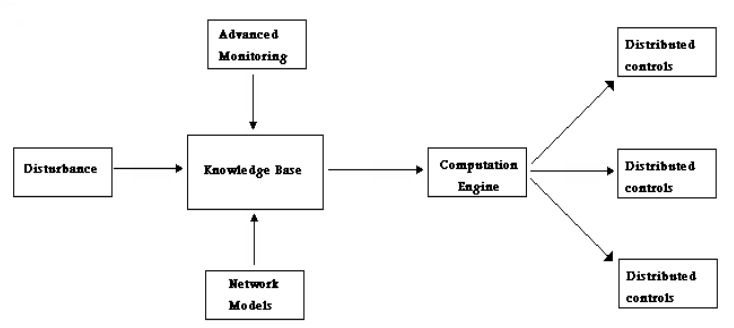

Fig. 4. Function block diagram of the ILS scheme

\section{Simulation Results}

In this section blackouts of generation units for a simple system that show in Figure 5 is simulating by Matlab Simulink. The load shedding strategy is applied to system and effect of blackouts and load shedding strategy on voltage and frequency stability will be study. For introduced power system we assume that the frequency permissible range is 59.5 to $60 \mathrm{~Hz}$ and D (damping factor) is 2 . Relation between amount of power imbalance and corresponding changes in angular speed during sudden changes of load $\Delta \mathrm{p}_{\mathrm{L}}$ is given by:

$$
-\Delta \mathrm{p}=2 \mathrm{H} \frac{\mathrm{d}(\Delta \omega)}{\mathrm{dt}}+\mathrm{D} \Delta \omega
$$

where $\Delta \mathrm{P}_{\mathrm{L}}$ is step change of load $\Delta \omega$ is change of angular speed, $\mathrm{H}$ is inertia constant, $\mathrm{D}$ is damping factor. Design of load shedding schemes to restore the frequency, requires a good estimation of frequency variation rate. Wherever a power imbalance occurs, the expression for the initial frequency variation rate is:

$$
\frac{\mathrm{df}}{\mathrm{dt}}=-\frac{\Delta \mathrm{p}}{2 \mathrm{H}}
$$

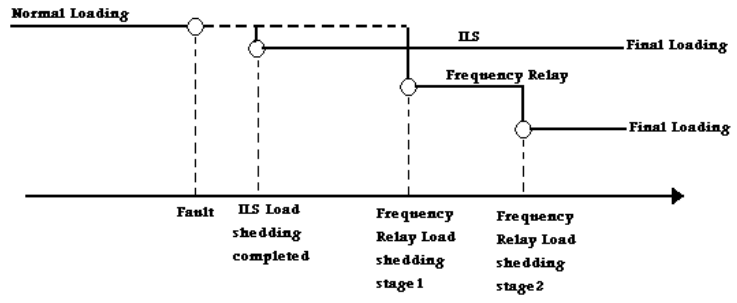

Fig. 5. ILS frequencies relay load shedding

In an interconnected power system consist of several generators Hsys is obtained from the equation below [6]:

$$
\text { Hsys }=\frac{\mathrm{H}_{1} \mathrm{MVA}_{1}+\mathrm{H}_{2} \mathrm{MVA}_{2}+\ldots+\mathrm{H}_{\mathrm{n}} \mathrm{MVA}_{\mathrm{n}}}{\mathrm{MVA}_{1}+\mathrm{MVA}_{2}+\ldots+\mathrm{MVA}_{\mathrm{n}}}
$$

The power system that simulate with Matlab Simulink is shown in the Figure.6. In simulation we forget the LFC and AVR loops. For simulating the load shedding algorithm that introduced in [5] simulation is implement for all blackouts that may occur in the introduced power system. Other system properties are: Demand $=4950 \mathrm{MW}, \mathrm{S}_{\mathrm{b}}=5500 \mathrm{MVA}$ and $\mathrm{f}=60 \mathrm{~Hz}$.

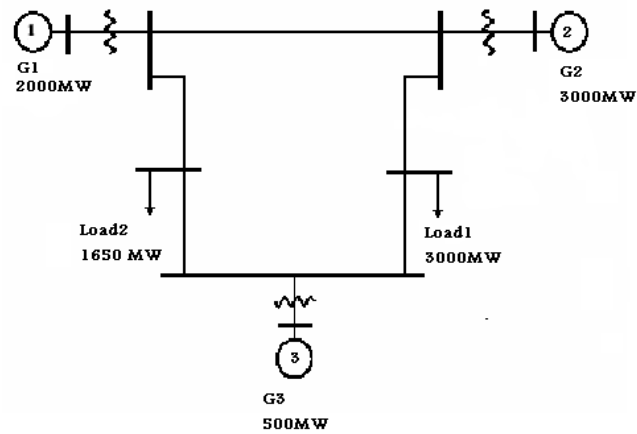

Fig. 6. Power system that represent for simulation

\begin{tabular}{llll}
\multicolumn{4}{c}{ TABLE II:CHARACTERISTICS OF SIMULATED POWER SYSTEM } \\
\hline \hline Number & Generator & Capacity & $\mathrm{H}$ \\
\hline 1 & $\mathrm{G}_{1}$ & 0.363 & 3.97 \\
2 & $\mathrm{G}_{2}$ & 0.545 & 4.18 \\
3 & $\mathrm{G}_{3}$ & 0.09 & 3.34 \\
\hline
\end{tabular}

Figures. 8-13 show the effects of blackouts that may occur in system frequency. From these Figures can see just in 3 state frequencies is decline under permissible range. There for load shedding implement for these states and for the states that frequency is in the permissible range, load shedding is not necessary. As can be seen from the results, most critical condition occurs when $G_{1}, G_{2}$ black out together. In this state, frequency is decay to $56 \mathrm{~Hz}$ in 1.5 second. Figures $14-16$ and Tables 3-5 shows that the load shedding is require to maintaining the frequency in the stable range. We can see after implementation of load shedding, frequency comeback to permissible range.

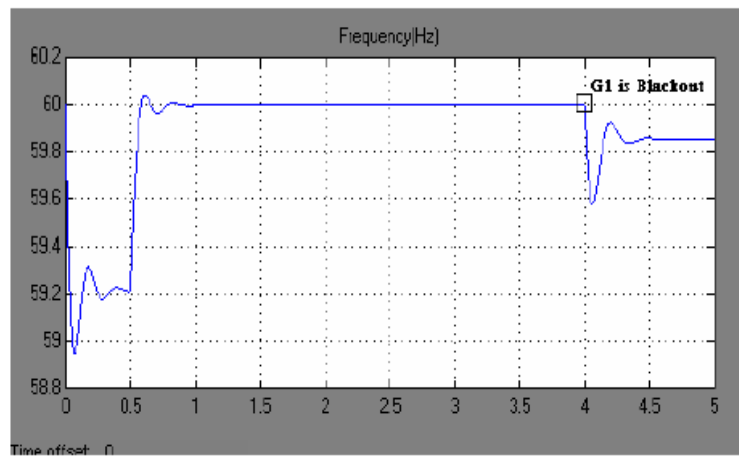

Fig. 8. Frequency drop that effect of blackout of $\mathrm{G}_{1}$

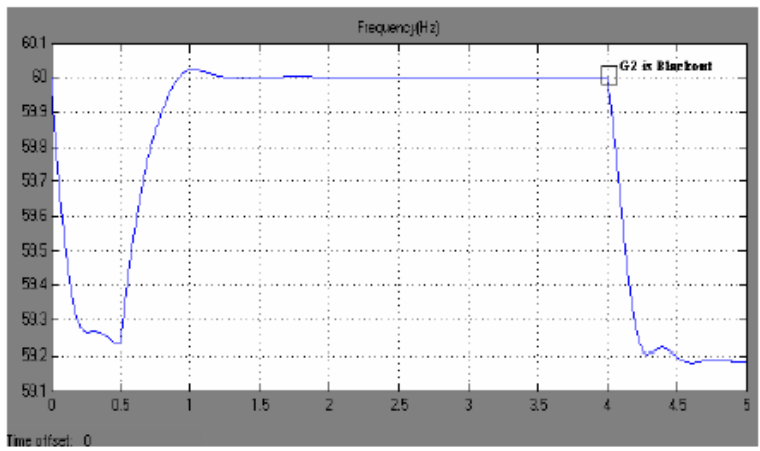

Fig. 9. Frequency drop that effect of blackout of $\mathrm{G}_{2}$ 


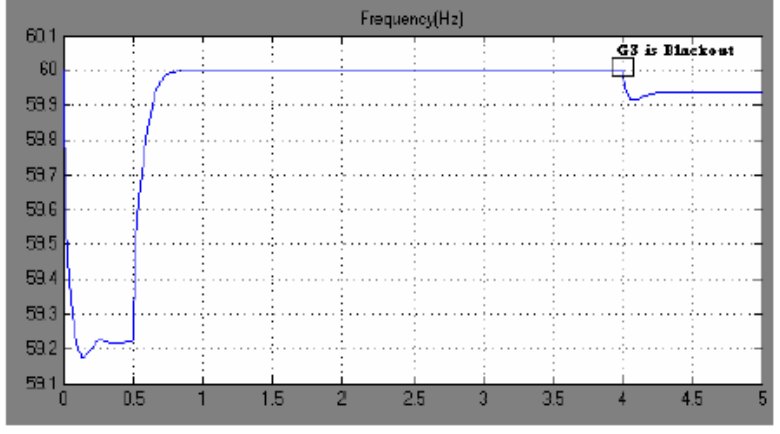

Fig. 10. Frequency drop when $\mathrm{G}_{1}$ is blackout

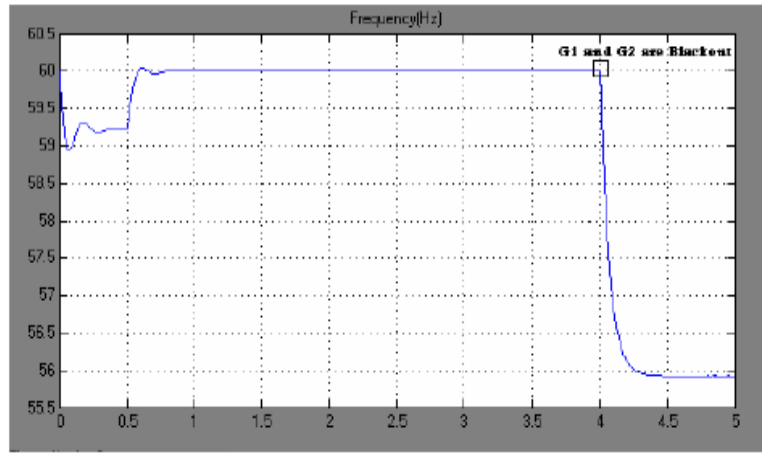

Fig. 11. Frequency drop when $\mathrm{G}_{1}$ and $\mathrm{G}_{2}$ Are blackout

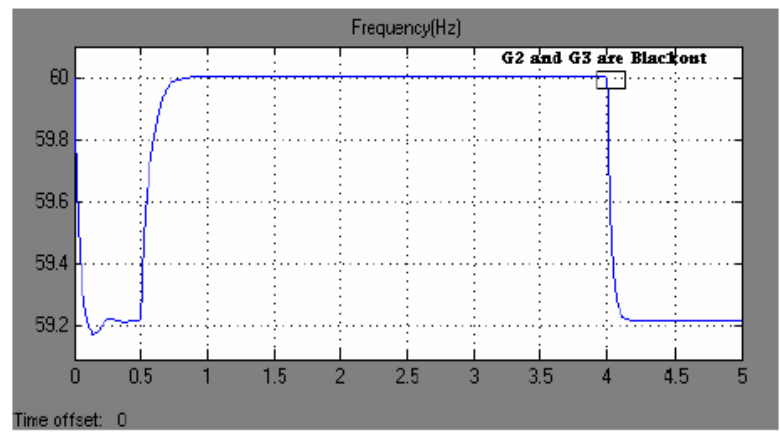

Fig. 12. Frequency drop when $G_{1}, G_{3}$ are blackout

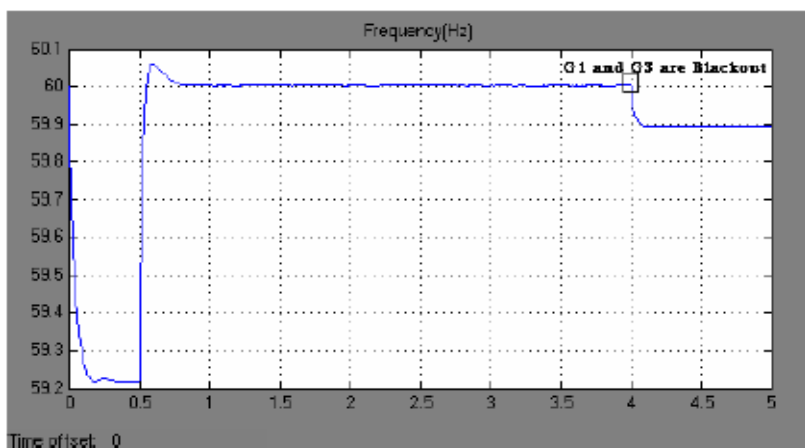

Fig. 13. Frequency drop when $\mathrm{G}_{2}, \mathrm{G}_{3}$ are blackout

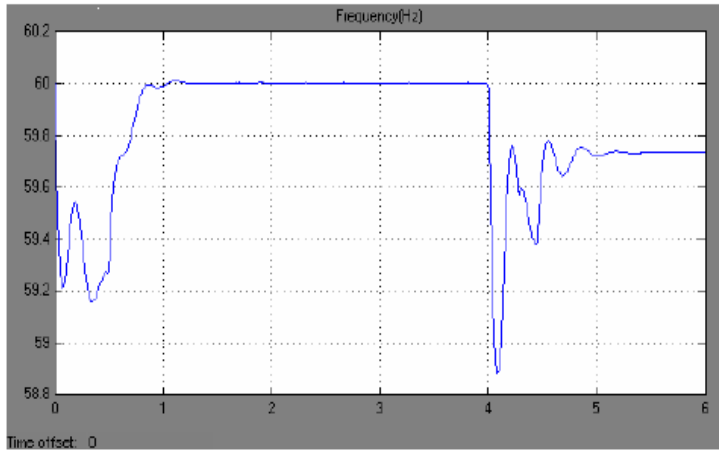

Fig. 14. Load shedding simulation for blackout of $\mathrm{G}_{2}$

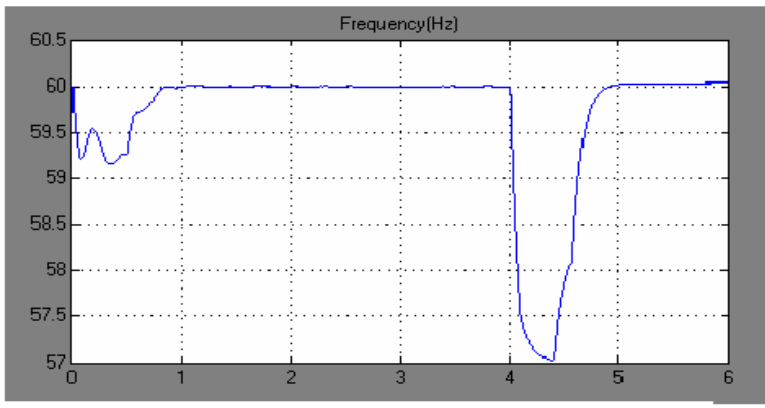

Fig. 15. Load shedding simulation for blackout of $\mathrm{G}_{1}, \mathrm{G}_{2}$ together

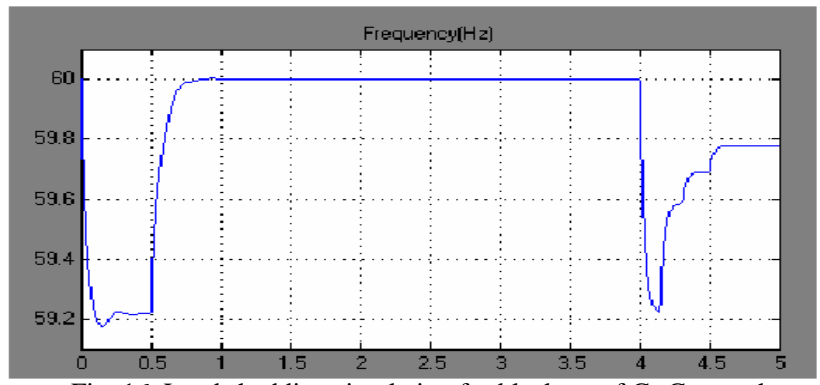

Fig. 16. Load shedding simulation for blackout of $\mathrm{G}_{2}, \mathrm{G}_{3}$ together

TABLE III: LOAD SHEDDING SIMULATION FOR BLACKOUT OF G2

\begin{tabular}{|c|c|c|c|c|c|}
\hline \multicolumn{2}{|c|}{ Relay setting } & $\begin{array}{c}\mathrm{f}_{\mathrm{ls}}=59.39 \mathrm{~Hz} \\
\text { Load shed }=20 \%\end{array}$ & \multicolumn{2}{|c|}{$\begin{array}{c}\mathrm{f}_{\mathrm{ls}}=58.90 \mathrm{~Hz} \\
\text { Load } \\
\text { shed }=20 \%\end{array}$} & $\begin{array}{c}\mathrm{f}_{\mathrm{ls}}=58.70 \mathrm{~Hz} \\
\text { Load } \\
\text { shed }=14 \%\end{array}$ \\
\hline & $\begin{array}{l}\text { Minimum } \\
\text { frequency } \\
(\mathrm{Hz})\end{array}$ & $\begin{array}{c}\text { Final } \\
\text { frequency } \\
(\mathrm{Hz})\end{array}$ & $\begin{array}{c}\text { Time at } \\
\text { min } \\
\text { frequency } \\
(\mathrm{Hz})\end{array}$ & $\begin{array}{l}\text { Over } \\
\text { load }\end{array}$ & $\begin{array}{l}\text { Maximum } \\
\text { shedding }\end{array}$ \\
\hline Calculated & $58.70 \mathrm{~Hz}$ & $60 \mathrm{~Hz}$ & $0.17 \mathrm{sec}$ & $54 \%$ & $54 \%$ \\
\hline Simulation & $58.88 \mathrm{~Hz}$ & $59.84 \mathrm{~Hz}$ & $0.088 \mathrm{sec}$ & $54 \%$ & $54 \%$ \\
\hline
\end{tabular}

TABLE IV: LOAD SHEDDING SIMULATION FOR BLACKOUT OF G1,G2 TOGETHER

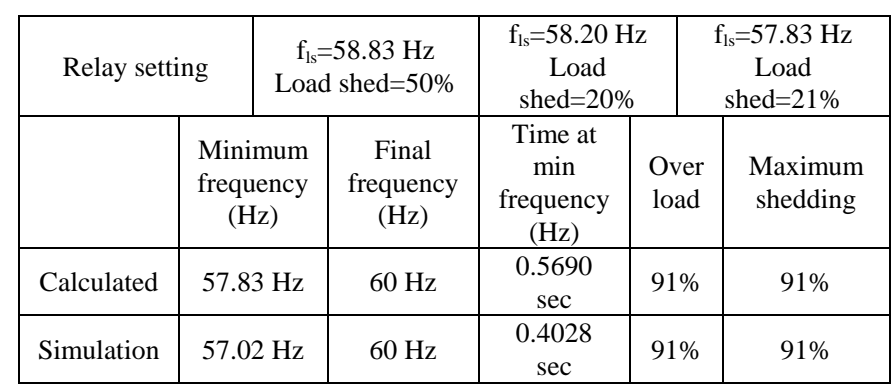

TABLE V:LOAD SHEDDING SiMULATION FOR BLACKOUT OF G2, G3 TOGETHER

\begin{tabular}{|c|c|c|c|c|c|c|}
\hline \multicolumn{2}{|c|}{ Relay setting } & \multicolumn{2}{c|}{$\begin{array}{c}\mathrm{f}_{\mathrm{ls}}=59.30 \mathrm{~Hz} \\
\text { Load shed=30\% }\end{array}$} & $\begin{array}{c}\mathrm{f}_{\mathrm{ls}}=58.84 \mathrm{~Hz} \\
\text { Load } \\
\text { shed=20\% }\end{array}$ & \multicolumn{2}{c|}{$\begin{array}{c}\mathrm{f}_{\mathrm{ls}}=58.59 \mathrm{~Hz} \\
\text { Load } \\
\text { shed=13.63\% }\end{array}$} \\
\hline & $\begin{array}{c}\text { Minimum } \\
\text { frequency } \\
(\mathrm{Hz})\end{array}$ & $\begin{array}{c}\text { Final } \\
\text { frequency } \\
(\mathrm{Hz})\end{array}$ & $\begin{array}{c}\text { Time at } \\
\text { min } \\
\text { frequency } \\
(\mathrm{Hz})\end{array}$ & $\begin{array}{c}\text { Over } \\
\text { load }\end{array}$ & $\begin{array}{c}\text { Maximum } \\
\text { shedding }\end{array}$ \\
\hline Calculated & $58.59 \mathrm{~Hz}$ & $60 \mathrm{~Hz}$ & $0.305 \mathrm{sec}$ & $63.63 \%$ & $63.63 \%$ \\
\hline Simulation & $59.20 \mathrm{~Hz}$ & $59.77 \mathrm{~Hz}$ & $0.145 \mathrm{sec}$ & $63.63 \%$ & $63.63 \%$ \\
\hline
\end{tabular}

\section{CONCLUSION}

A simple power system was simulated with the Matlab Simulink software. All blackout conditions that may occur have been investigated. Under frequency load shedding strategy implement for conditions that frequency decline under 
the permissible range. According to simulation results, proper load shedding when a blackout occurs can prevent of voltage and frequency collapse and blackouts of other generators. With the compare of simulating results and calculated results can be seen that they are close together. Some tolerances between them is due to the approximations in calculation processes. Simulation of power systems can help to design a proper and reliable load shedding strategy. The results of simulations can be use in frequency relay settings or use for the initial data in the intelligent load shedding methods.

\section{REFERENCES}

[1] D. Craciun, S. Ichim, and Y. Besanger, "A new soft load shedding: Power system stability with contribution from consumers," IEEE/PTC, pp. 1-6, June/July 2009.

[2] D.Andersson, P.Elmersson, A.Junti, Z.Gajie, D.Karlsson, and L.Fabiano, "Intelligent load shedding to counteract power system instability," IEEE/PES, pp. 570-574, 2004.

[3] M. Guerreiro, D. Foito, and A. Cordeiro, "A speed controller for a two-winding induction motor based on diametrical inversion," IEEE Tran. on Ind. Elec., vol.57, no.1, pp.449-456, January 2010.

[4] S. Su and T. Kazuyuki, "An efficient voltage stability ranking using load shedding for stabilizing unstable contingencies," IEEE/UPEC, pp. 1-5, Sept. 2009.

[5] S. Jier and C.C. Huang, "An automatic load shedding scheme including pumped storage units," IEEE Trans. On Eng. Conv., vol.15, no.4, pp. 427-432, Dec. 2000

[6] H. Seyedi, M. Sanaye-Pasand, and M. R. Dadashzadeh, "Design and simulation of an adaptive load shedding algorithm using a real network," IEEE/POWERI, pp. 1-5, June 2006.
[7] G. B. Shrestha and G. B. K. C. Lee, "Load shedding schedules considering probabilistic outages," IEEE/IPEC, vol.2, pp. 950-955, Nov./Dec. 2005.

[8] A. A. M. Zin, H. M. Hafiz, and W. K.Wong, "Static and dynamic under frequency load shedding: A comparison," IEEE/POWERCON, pp. 941-945, November 2004.

[9] N. Perumal and C. C. Ying, "A proposed strategy of implementation for load shedding and load recovery with dynamic simulationsm," IEEE/PECON, pp. 185-189, 2004.

[10] F. Shokooh, J. J. Dai, S. Shokooh, J. Tastet, H. Castro, T. Khandelwal, and G. Donner, "An intelligent load shedding (ILS) system application in a large industrial facility," IEEE/IAS, pp. 417-425, 2005.

Ghazanfar Shahgholian was born in Esfahan, Iran, on Dec. 7, 1968. He graduated in electrical engineering from Isfahan University of Technology (IUT), Esfahan, Iran, in 1992. He received the M.Sc and PhD in electrical engineering from University Tabriz, Tabriz, Iran in 1994 and Science and Research Branch, Islamic Azad University, Tehran, Iran, in 2006, respectively. He is now an associate professor at Department of Electrical Engineering, Faculty of Engineering, Islamic Azad University Najafabad Branch. He is the author of 100 publications in international journals and conference proceedings. His teaching and research interests include application of control theory to power system dynamics, power electronics and power system simulation.

Mahdi Ebrahimi-Salari received the B.Sc. degree in electrical engineering from Islamic Azad University, Bojnord branch, Iran, in 2007 and the M.Sc. degree from Najaf Abad branch, Islamic Azad University, in 2009. He is a member of the Young Researchers Club. His research interests include design and modeling of electrical machines. 
EHV transmission systems using neural networks," Electric Power System Research, vol. 36, no. 1, pp. 57-66, 1996.

[11] P. K. Dash, A. K. Pradhan, G. Panda, and A. C. Liew, "Adaptive Relay Setting for Flexible AC Transmission Systems (FACTS)," IEEE Trans. Power Delivery, vol. 15, no. 1, 2000.

[12] D. Novosel, B. Bachmann, D. Hart, Y. Hu, M. M. Saha, "Algorithm for Locating Faults on Series Compensated Lines Using Neural Network and Deterministic Methods," IEEE Trans. Power Delivery, vol. 11, no. 4, 1996.

[13] K. Hornik, M. Stinchcombe, and H. White, "Multilayer feedforward networks are universal approximators," Neural Networks, vol. 2, no. 5, pp. 359-366, 1989.

[14] J. Park and I. W. Sandberg, "Universal approximation using radial-basis-function-networks," Neural Computation, vol. 3, no. 2, pp. 246-257, 1991.

[15] J. F. Kolen and S. C. Kremer. "A Field Guide to Dynamical Recurrent Networks," Wiley-IEEE Press, 2001.

[16] D. Coyle, G. Prasad, and T. M. McGinnity, "A time-series prediction approach for feature extraction in a brain-computer interface," IEEE Trans. on Neural Systems and Rehabilitation Engineering, vol. 13, no. 4, pp. 461-467, 2005.

[17] H. Jaeger, "The echo state approach to analysing and training recurrent neural networks," GMD report 148, German National Research Center for Information Technology, 2001.

[18] H. Jaeger, "A tutorial on training recurrent neural networks. Covering BPTT, RTRL, EKF, and the Echo State Network Approach," GMD report 159. German National Research Center for Information Technology, 2002.
[19] H. Jaeger, "Adaptive nonlinear system identification with echo state networks" In Advances in neural information processing systems: vol. 15, pp. 593-600. Cambridge, MA: MIT Press.

[20] G. K. Venayagamoorthy, "Online design of an echo state network based wide area monitor for a multimachine power system," Neural Networks, vol. 20, pp. 404-413, 2007.

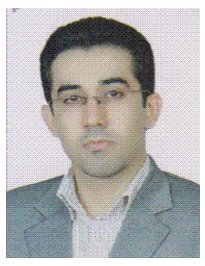

Alireza Solat was born in Saveh, Iran in 1985. He received the B.Sc. and M.Sc. degrees from Bu-Ali Sina University, Hamedan, Iran both in Electrical Engineering in 2008 and 2011 respectively. He is currently pursuing the Ph.D. degree in power system engineering at Islamic Azad University, Science and Research Branch, Tehran, Iran since Sep. 2011. His research interests are FACTs, power system operation and control, power system protection, as well as signal processing and artificial intelligence applications in power systems.

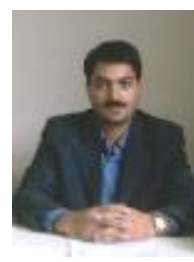

Ali Deihimi was born in Hamedan, Iran in 1971. He received the B.Sc. and M.Sc. degrees both from Ferdowsi University of Mashhad, Iran in 1994 and 1996 respectively and Ph.D. degree from University of Tehran, Iran in 2002, all in electrical power engineering. Dr. Deihimi is currently an Assistant Professor in the Department of Electrical Engineering Bu-Ali Sina University, Hamedan, Iran. His main research interests are power system analysis and operation, power system protection, power quality, reactive power control and FACTs devices. 